\title{
How long is cessation of preoperative smoking required to improve postoperative survival of patients with pathological stage I non-small cell lung cancer?
}

\author{
Toshiyuki Shima ${ }^{1,2}$, Tomonari Kinoshita ${ }^{1,2}$, Mao Uematsu ${ }^{1}$, Naomichi Sasaki ${ }^{1}$, Yusuke Sugita ${ }^{1}$, Reiko Shimizu ${ }^{1}$, \\ Masahiko Harada ${ }^{1}$, Tsunekazu Hishima ${ }^{3}$, Hirotoshi Horio ${ }^{1}$ \\ ${ }^{1}$ Department of Thoracic Surgery, Tokyo Metropolitan Cancer and Infectious Diseases Center Komagome Hospital, Tokyo, Japan; ${ }^{2}$ Division \\ of General Thoracic Surgery, Department of Surgery, Keio University School of Medicine, Tokyo, Japan; ' Department of Pathology, Tokyo \\ Metropolitan Cancer and Infectious Diseases Center Komagome Hospital, Tokyo, Japan \\ Contributions: (I) Conception and design: T Shima, T Kinoshita; (II) Administrative support: M Harada, T Hishima, H Horio; (III) Provision of \\ study materials or patients: T Kinoshita; (IV) Collection and assembly of data: M Uematsu, N Sasaki, Y Sugita, R Shimizu; (V) Data analysis and \\ interpretation: T Shima, T Kinoshita; (VI) Manuscript writing: All authors; (VII) Final approval of manuscript: All authors. \\ Correspondence to: Tomonari Kinoshita. Department of Thoracic Surgery, Tokyo Metropolitan Cancer and Infectious Diseases Center Komagome \\ Hospital, 3-18-22, Honkomagome, Bunkyo-ku, Tokyo 113-8677, Japan. Email: kinotomo0415@gmail.com.
}

Background: Smoking can cause non-small cell lung cancer (NSCLC). However, the effects of preoperative smoking on tumor progression are not well-known. In addition, the duration of smoking cessation that can provide NSCLC patients with smoking history similar postoperative prognosis as that of nonsmokers remains unknown. This study aimed to investigate the period of smoking cessation that may "compensate" for past smoking history regarding postoperative survival in cases of resected pathological stage I NSCLC by examining the relationship between clinicopathological factors and preoperative smoking. Methods: We retrospectively examined clinicopathological factors including preoperative smoking status and postoperative survival in 453 patients with pathologically proven stage I NSCLC at our Institute. Smoking status was evaluated using the following four parameters: cigarettes per day, number of years of smoking, pack-years, and number of years since smoking cessation.

Results: Pathological factors that reflect tumor invasiveness including vascular invasion (VI) and pleural invasion (PL) were associated with the degree of preoperative smoking in adenocarcinomas, particularly invasive diameters of $2-3 \mathrm{~cm}$. Such a relationship was not identified for non-adenocarcinomas. Heavy smoking status was significantly related to PL in lepidic or papillary predominant adenocarcinomas and to VI in acinar or solid predominant adenocarcinomas. Former smokers who quit smoking for $\geq 10$ years had similar postoperative survival as non-smokers for adenocarcinoma $\leq 3 \mathrm{~cm}$.

Conclusions: Accumulative smoking habit correlated with VI and PL, particularly in 2-3 cm adenocarcinoma, whereas larger adenocarcinomas and non-adenocarcinomas of any size appear to grow and become invasive independent of preoperative smoking status. Longer smoking cessation $\geq 10$ years can result in postoperative survival similar to that of non-smokers with adenocarcinomas $\leq 3 \mathrm{~cm}$. Current smokers should quit smoking immediately to ensure longer survival even though they suffer from small-sized lung adenocarcinomas in the future.

Keywords: Smoking cessation; lung adenocarcinoma; pathological stage I

Submitted Mar 23, 2020. Accepted for publication Aug 28, 2020.

doi: $10.21037 /$ tlcr-20-465

View this article at: http://dx.doi.org/10.21037/tlcr-20-465 


\section{Introduction}

The number of surgical cases of non-small cell lung cancer (NSCLC) is increasing worldwide due to the increasing use of computed tomography (CT) $(1,2)$. However, despite complete resection for early-stage NSCLC, lung cancer has a high frequency of recurrence (3). Multiple studies have demonstrated that some perioperative clinicopathological factors, such as pleural invasion (PL), vascular invasion (VI), and lymphatic permeation (LY), were identified as predictive markers of tumor relapse in resected early stage NSCLC (4-6). Indeed, PL was confirmed as an upstaging factor of "T" in the seventh TNM staging of lung cancer (7). In other words, these factors as well as nodal metastasis are representative surrogate markers that can reflect tumor invasiveness in early stage NSCLC.

Non-adenocarcinomas, such as squamous cell carcinomas, are generally considered to be associated with heavy smoking (8). Low yield filter cigarettes with deeper and more frequent inhalation may result in increased delivery of carcinogens to the lung peripheries. This may contribute to an increased incidence of adenocarcinoma of the lung (9). Non-smokers with specific genetic features too can develop lung adenocarcinoma (10). Some reports have stated that preoperative smoking cessation can prevent perioperative complications, such as postoperative pneumonia $(11,12)$. However, the influence of preoperative smoking on the progression and invasiveness of early stage NSCLC remains unclear.

Additionally, there is an increase in the number of smokers who quit smoking owing to the worldwide educational efforts regarding the importance of smoking cessation as a means of preventing lung as well as other cancers $(8,13)$. Unfortunately, some ex-smokers may still be diagnosed with NSCLC. In order to encourage current smokers to quit smoking, we should be able to provide information regarding the duration of smoking cessation prior to the diagnosis of stage I NSCLC that may result in outcomes and prognosis in smokers similar to that in nonsmokers. However, this information is currently unavailable.

In this study, we examined the relationship between prognostic factors and preoperative smoking status in cases of resected pathological stage I NSCLC. We also investigated the period of smoking cessation that would make up for the past smoking history in terms of postoperative survival.

We present the following article in accordance with the STROBE reporting checklist (available at http://dx.doi. org/10.21037/tlcr-20-465).

\section{Methods}

\section{Patients}

This study was approved by our institutional review board in March 2020 (approved number \#2483). The requirement of informed consent was waived due to the retrospective design of the study and because no personally identifiable information was collected. Clinical data including smoking history were recorded by medical staff (nurses and/or doctors) and used for statistical analysis. All procedures performed in this study were in accordance with the Declaration of Helsinki (as revised in 2013)

Overall, 453 patients with pathological stage I NSCLC who underwent complete resection and systematic lymph node dissection at our Institute between January 2004 and December 2018 were enrolled in this study. The cases with invasive diameter $>4 \mathrm{~cm}$ or lymph node metastasis were excluded based on pathological examinations. Segmentectomy with systematic lymphadenectomy was the procedure included as limited surgery in our retrospective study. Patients who underwent wedge resection and/or neoadjuvant chemotherapy were excluded. Patients with a follow-up of less than one year were excluded (Table 1, Figure 1).

\section{Pathological evaluation}

All slides of resected specimens were evaluated. All specimens were fixed in $10 \%$ formalin and embedded in paraffin. Serial 4- $\mu$-thick sections were stained with hematoxylin/eosin and Elastica van Gieson to assess the degree of PL and VI. When required, we also stained them with D2-40 to evaluate the extent of LY. All cases were reviewed according to the $4^{\text {th }}$ edition of the World Health Organization histological classification and staged according to the $8^{\text {th }}$ edition of the TNM classification of the Union for International Cancer Control $(14,15)$. Invasive size confirmed by pathologists was used as tumor size according to the current TNM staging.

\section{Follow-up assessments}

Patients were followed-up at our outpatient department quarterly in the first 2 years after resection and semiannually thereafter. CT scans of the chest and upper 
Table 1 Characteristics of the enrolled patients

\begin{tabular}{lc}
\hline Factors & $\mathrm{n}=453$ \\
\hline Sex, male/female & $242 / 211$ \\
Age, median (range) & $71[34-88]$ \\
Observation period, mean months (range) & $58.7[12-193]$ \\
Smoking, ever/never & $289 / 164$ \\
COPD, present/absent & $103 / 350$ \\
Surgery, lobectomy/segmentectomy & $396 / 57$ \\
Histological type, AD/SQ/ADSQ/others & $325 / 97 / 10 / 21$ \\
Lymphatic permeation, present/absent & $65 / 388$ \\
Vascular invasion, present/absent & $154 / 299$ \\
Pleural invasion, present/absent & $111 / 342$ \\
Invasive size, $\leq 3$ cm/>3 cm & $365 / 88$ \\
T stage, 1mi/1a/1b/1c/2a & $59 / 45 / 102 / 88 / 159$ \\
\hline COPD, chronic obstructive pulmonary disease; AD, adenocarcinoma; SQ, squamous cell carcinoma; ADSQ, adenosquamous carcinoma.
\end{tabular}

COPD, chronic obstructive pulmonary disease; $A D$, adenocarcinoma; $S Q$, squamous cell carcinoma; $A D S Q$, adenosquamous carcinoma.

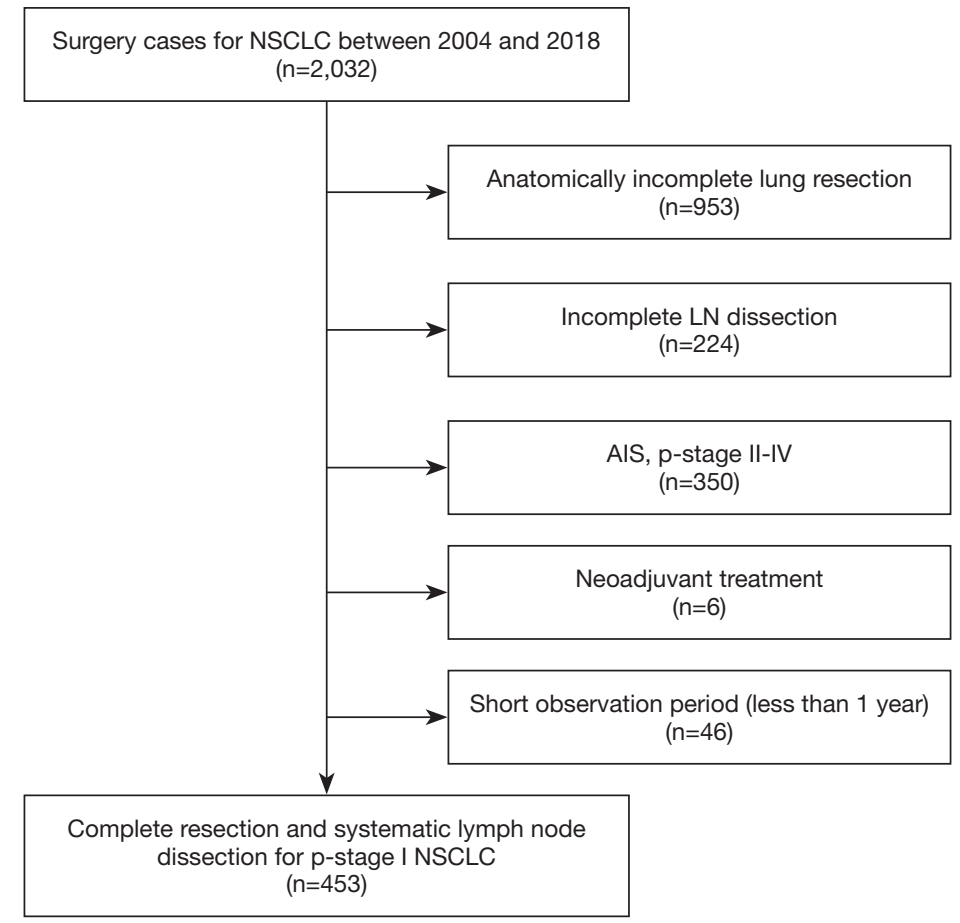

Figure 1 Study flow chart. NSCLC, non-small cell lung cancer; LN, lymph node; AIS, adenocarcinoma in situ. 
abdomen were routinely performed at every scheduled outpatient department visit during the follow-up. Additionally, CT scans or magnetic resonance imaging of the brain were also routinely performed in the same schedule. The period of overall survival (OS) was defined as the interval between the date of surgical resection and the date of death or the last follow-up. The length of recurrence-free survival (RFS) was defined as the interval between the date of surgical resection and the date of the diagnosis of initial metastasis, death, or the last follow-up. Disease-specific survival (DSS) was defined as the period between the date of surgery and the date of lung cancerassociated death or the date of the last follow-up.

\section{Statistical analyses}

Survival curves were plotted using the Kaplan-Meier method. The log-rank test was used to compare the postoperative survival. For survival analyses, univariate and multivariate analyses were performed using the Cox proportional hazards model. All variables with $\mathrm{P}<0.1$ on univariate analysis were entered into the multivariate forward-backward stepwise model. Two-category comparisons were performed using chi-square or Fisher's exact test, and Mann-Whitney U-test for quantitative data. All tests were two-sided, and statistical significance was defined as $\mathrm{P}<0.05$. All analyses were performed using SPSS v25 (IBM Inc., Armonk, NY, USA).

\section{Results}

\section{Pathological factors that would promote tumor progression in pathological stage I NSCLC}

In the survival analyses of 453 patients, median survival period was 137 months (95\% confidence interval, 130-144 months). Five- and 10 -year survival rates were $84.9 \%$ and $68.4 \%$ for OS, and $75.8 \%$ and $62.6 \%$ for RFS, respectively. Among 325 adenocarcinoma patients, 49 patients (15.1\%) died and $49(15.1 \%)$ patients had recurrent tumors. In 128 non-adenocarcinoma patients, 34 (26.6\%) died and 23 cases $(18.0 \%)$ relapsed. The results of the univariate and multivariate analysis of OS, RFS, and DSS, according to histological types, are summarized in Tables 2,3. In univariate survival analyses of adenocarcinomas, larger invasive size and presence of LY, VI, and PL, in addition to smoking history, significantly correlated with unfavorable prognosis. VI and PL were identified as independent prognostic factors among adenocarcinoma patients in multivariate analyses. Similar findings were observed in cases of non-adenocarcinoma. These findings indicate that the pathological factors, LY, VI, and PL, are not only prognostic factors but can also act as surrogate markers of tumor malignancy.

\section{Relationship between pathological factors and smoking status}

The statistical relationship between clinical and pathological factors among patients with adenocarcinoma and nonadenocarcinoma are presented in Table 4. While not only invasive tumor size but also tobacco habit was significantly correlated with pathological factors among adenocarcinoma patients, there was no such relationship in patients with non-adenocarcinomas. These results indicate that smoking may contribute to the progression of adenocarcinoma.

\section{Long-term smoking accelerates tumor progression in pathological stage I adenocarcinoma}

In the clinical data, we focused on the smoking history of patients who underwent resection for stage I NSCLC. Smoking status was evaluated using the following four parameters: cigarettes per day, number of years of smoking, pack-years, and number of years since smoking cessation. As summarized in Table 5, LY, VI, and PL were significantly associated with accumulative smoking habit in patients with adenocarcinoma. Particularly, long-term cessation of smoking could potentially mitigate local invasion of adenocarcinoma. In contrast, no apparent relationship between the duration of smoking and these factors was identified in non-adenocarcinomas.

\section{Smoking influence on tumor progression according to invasive size in adenocarcinoma}

Generally, as the invasive part of a tumor increases, its malignant characteristics accelerate, as is seen in " $T$ " factors of TNM staging (16). We classified stage I adenocarcinomas into three groups according to the invasive size: $\leq 2,2-3$, and $3-4 \mathrm{~cm}$. Although no strong effects of preoperative smoking on postoperative OS and DSS were confirmed, patients with $\leq 3 \mathrm{~cm}$ adenocarcinoma who had never smoked had favorable RFS (Figure 2). In terms of the relationship between smoking status and pathological factors, PL correlated with accumulative smoking in $\leq 2 \mathrm{~cm}$ adenocarcinomas; both VI and PL were related to heavy 


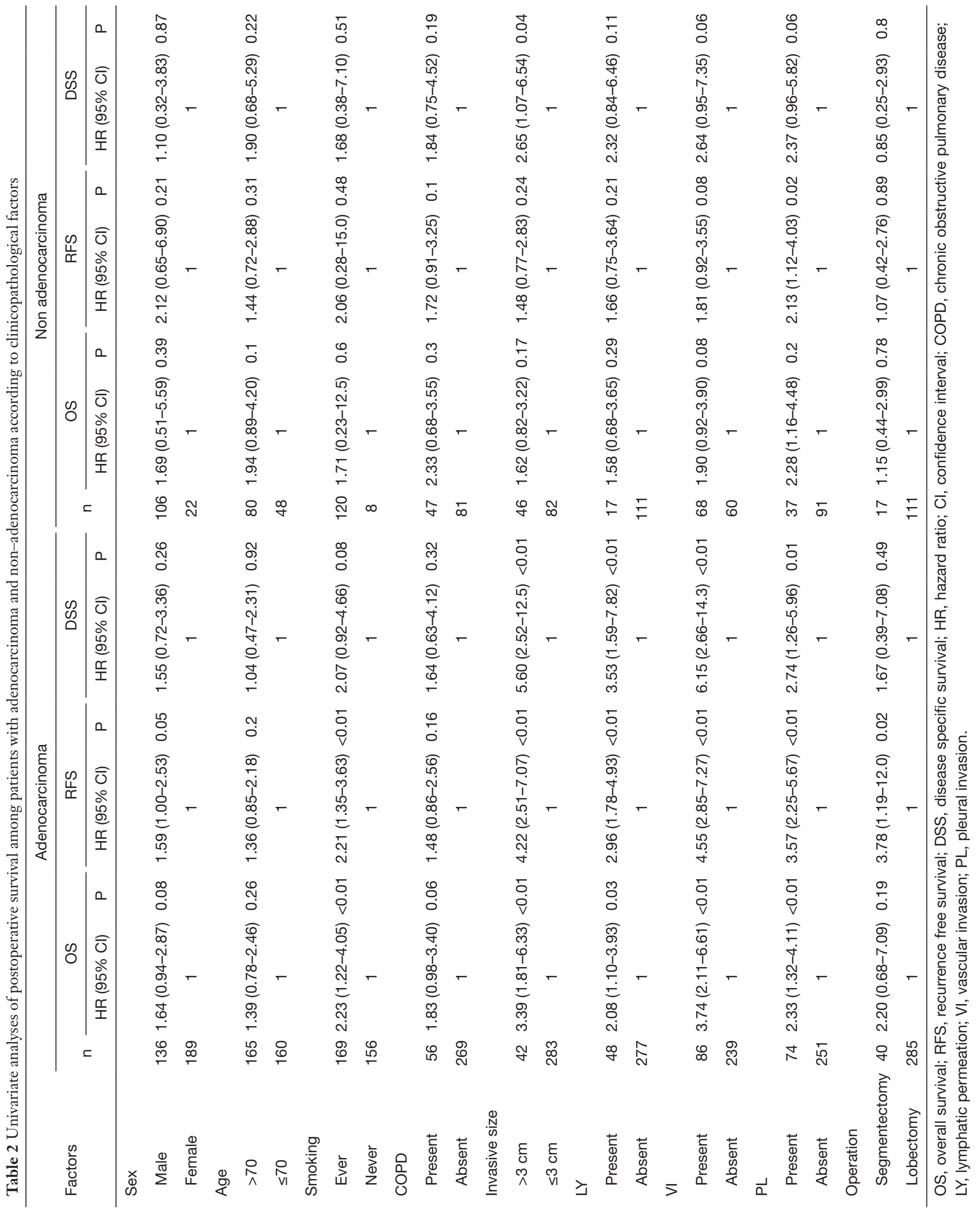




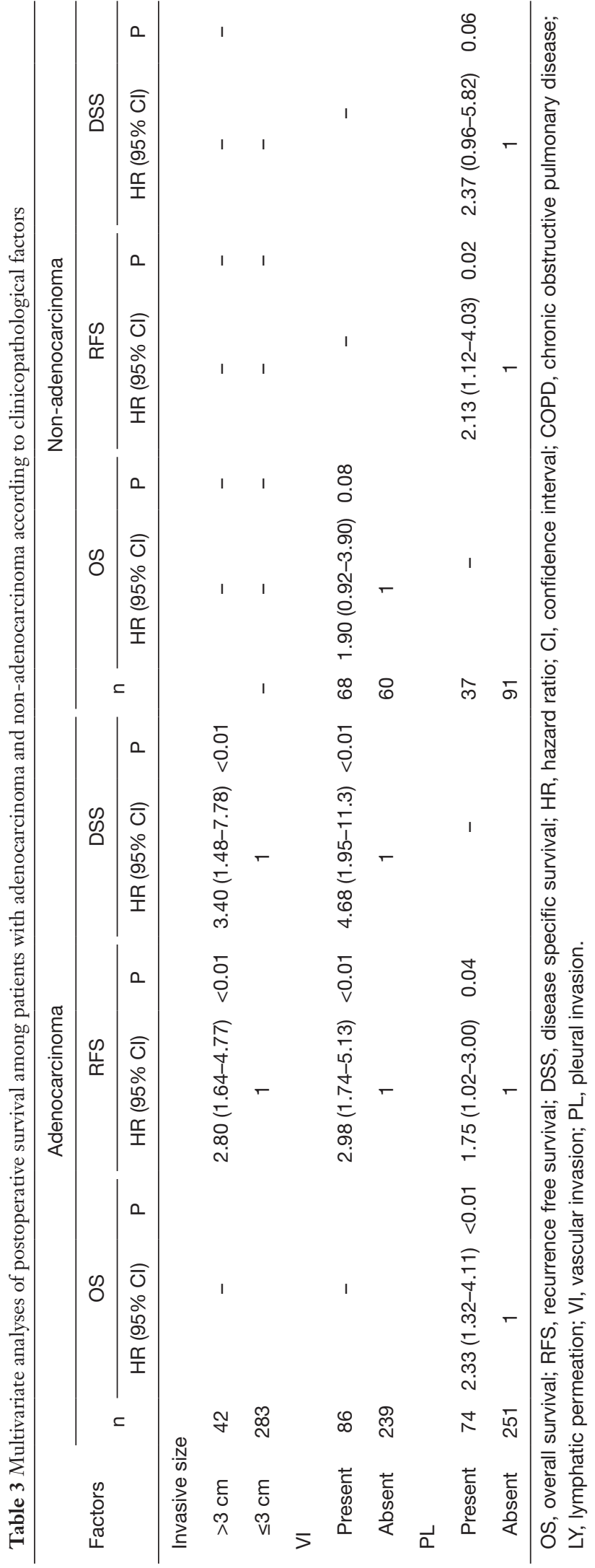

and current smoking in adenocarcinomas of $2-3 \mathrm{~cm}$; and no apparent relationship was identified between them in adenocarcinomas $>3 \mathrm{~cm}$ (Table 6).

\section{Histological subtypes of adenocarcinoma and smoking babit}

Histological predominant subtype of adenocarcinoma should be described in the pathological report (17). The cases in this study included 127 lepidic, 115 papillary, 62 acinar, 17 solid, and 4 mucinous adenocarcinomas. There were no cases of micropapillary predominant adenocarcinoma. Adenocarcinomas with micropapillary components are reported to have poorer prognosis than the others and have a higher frequency of recurrence (18); therefore, we evaluated the effects of smoking according to the presence/absence of micropapillary components as well as based on the main subtype of adenocarcinoma. Although postoperative survival was not affected by smoking history in each subtype (Table 7), PL correlated with heavy smoking status in lepidic and papillary adenocarcinomas and VI correlated with smoking in acinar and solid adenocarcinomas. Mucinous invasive adenocarcinomas were not analyzed owing to the small number of cases (Table 8).

\section{Smoking cessation for at least 10 years may result in similar prognosis as that in non-smokers in adenocarcinomas $\leq 3 \mathrm{~cm}$}

According to our results, smoking accelerates tumor progression in adenocarcinomas $\leq 3 \mathrm{~cm}$. Early smoking cessation is believed to contribute to reducing the perioperative complications and also to prolonging postoperative survival following NSCLC treatment (19). However, the duration of smoking cessation that would provide any survival benefit following surgical resection of lung adenocarcinoma is unclear. When former smokers with $\geq 5$ years of smoking cessation (y.c.) were combined with non-smokers (never +5 y.c.), no apparent correlation with the pathological factors was observed in each of the adenocarcinoma size group. Statistical differences in postoperative survival were also not detected between ever-smokers (current or former smokers with $<5$ years of smoking cessation) and never +5 y.c. both in adenocarcinomas $\leq 2$ and $2-3 \mathrm{~cm}$. However, cases of never +10 y.c., +15 y.c., and +20 y.c. were related to pathological factors (particularly in adenocarcinomas of $2-3 \mathrm{~cm}$ ), and these patients had significantly better prognosis than ever- 


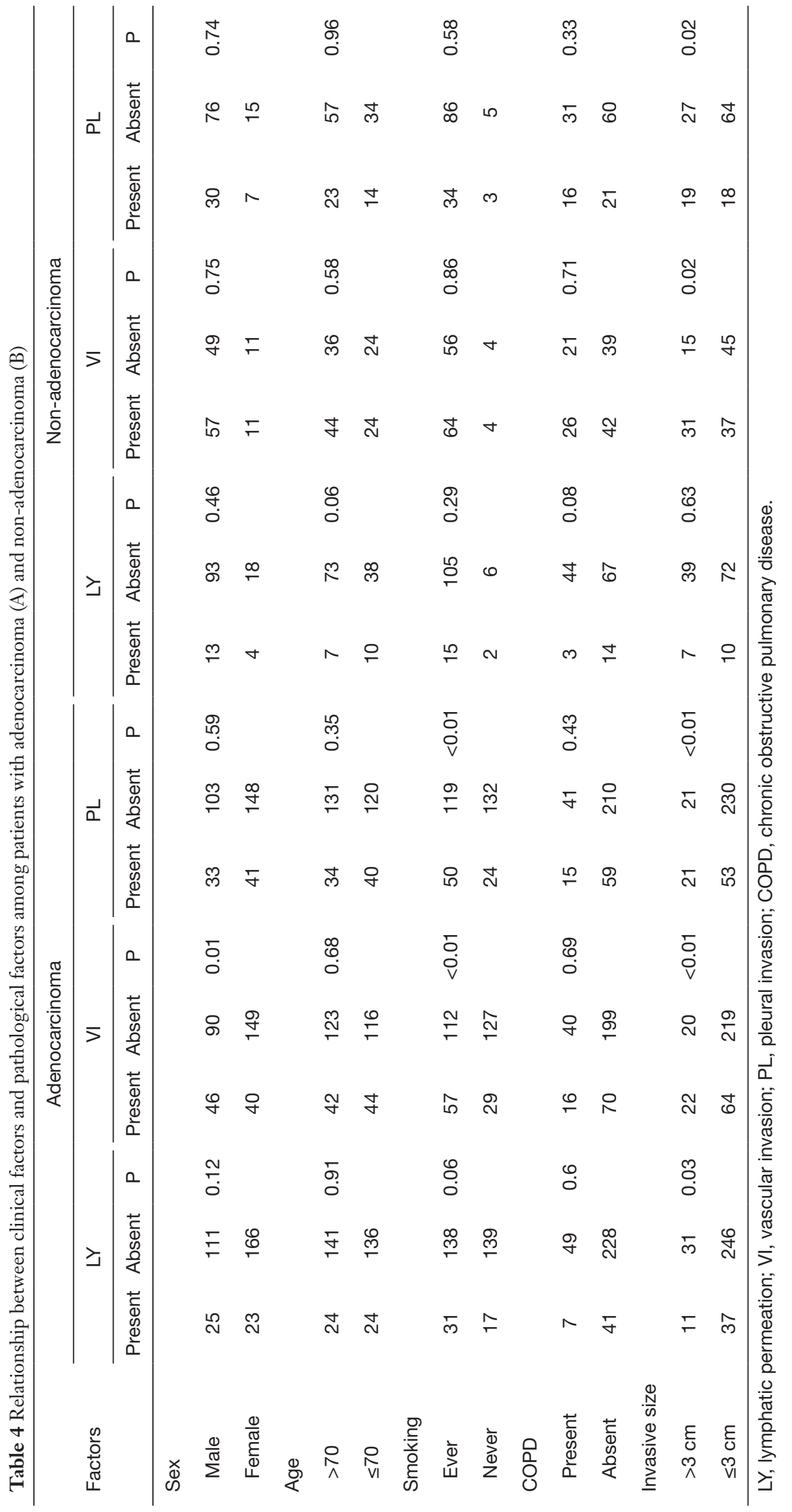




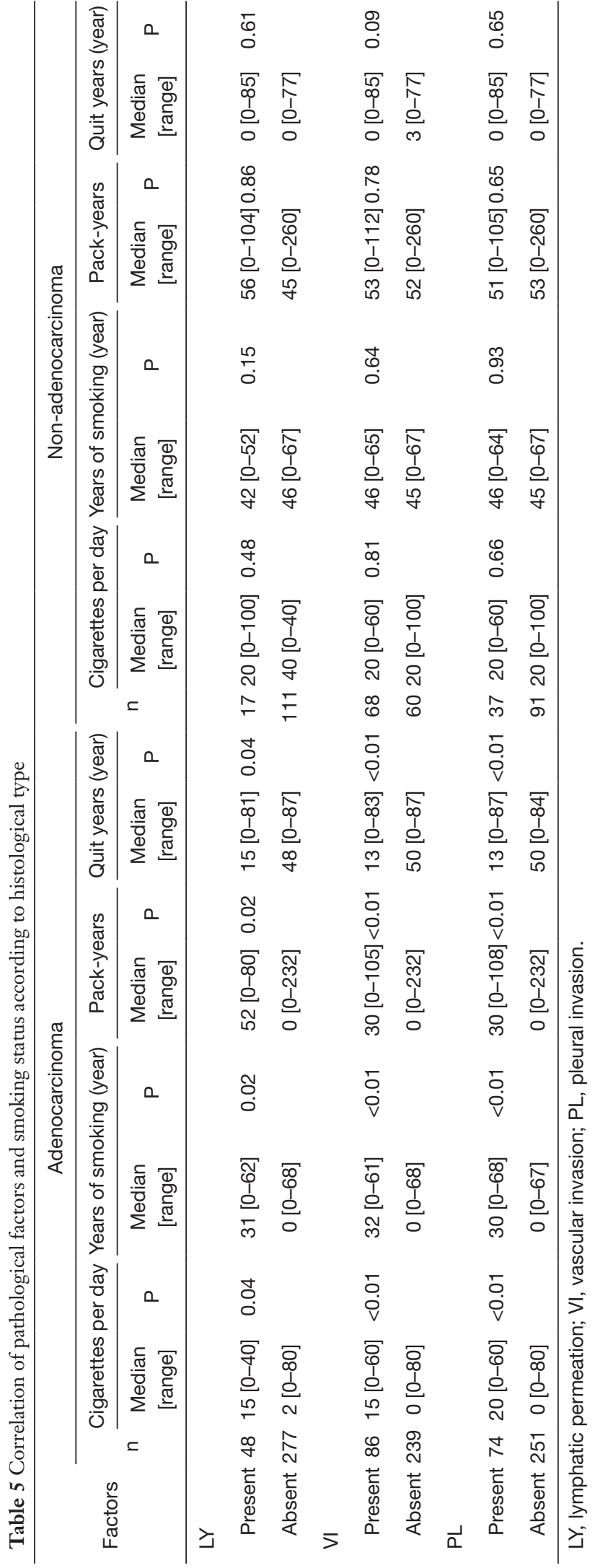

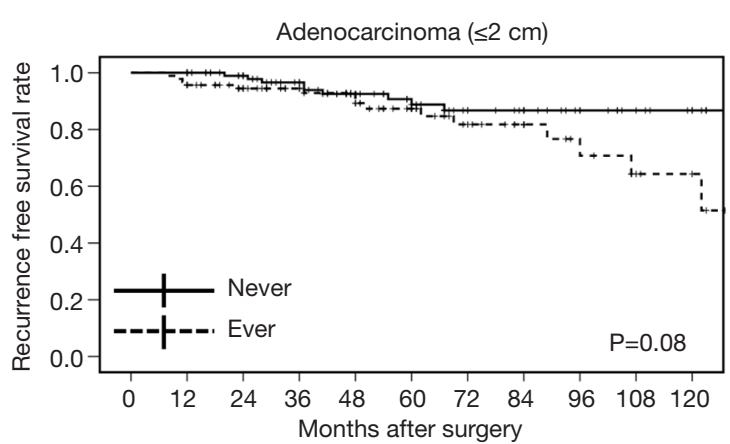

Patients at risk
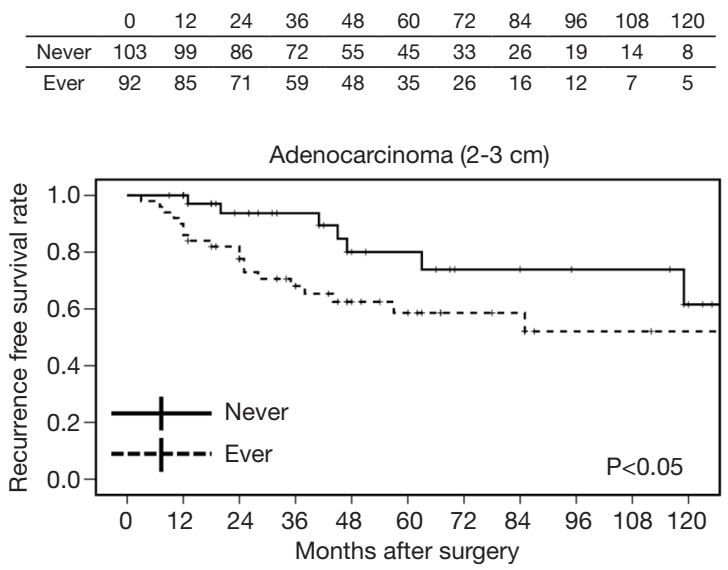

Patients at risk
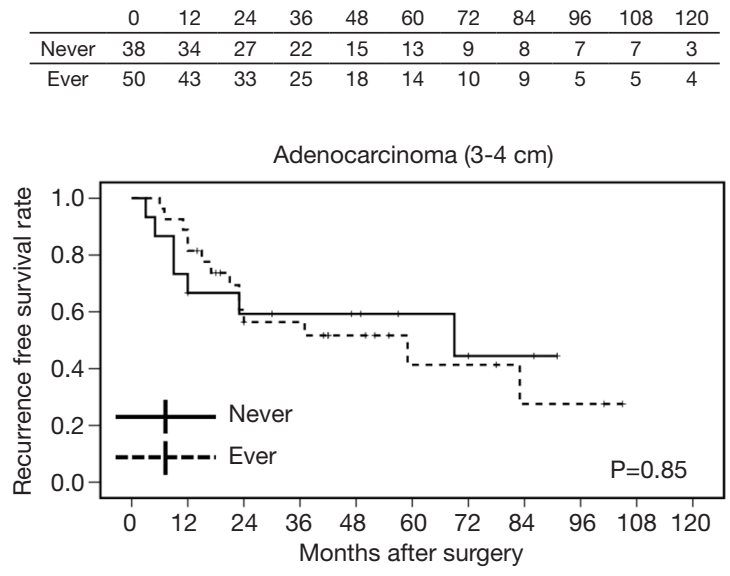

Patients at risk

$$
\begin{array}{cccccccccccc} 
& 0 & 12 & 24 & 36 & 48 & 60 & 72 & 84 & 96 & 108 & 120 \\
\hline \text { Never } & 14 & 9 & 8 & 7 & 6 & 4 & 2 & 2 & 0 & 0 & 0 \\
\hline \text { Ever } & 28 & 22 & 12 & 12 & 8 & 4 & 4 & 2 & 2 & 0 & 0
\end{array}
$$

Figure 2 Recurrence-free survival curves of patients with adenocarcinomas for various invasive tumor sizes $(\leq 2,2-3,3-4 \mathrm{~cm})$ and smoking status (ever $v s$. never). 
Table 6 Correlation of pathological factors and smoking status according to invasive size of adenocarcinoma

\begin{tabular}{|c|c|c|c|c|c|c|c|c|c|}
\hline Factors & $\mathrm{n}$ & \multicolumn{2}{|c|}{ Cigarettes per day } & \multicolumn{2}{|c|}{ Years of smoking (year) } & \multicolumn{2}{|c|}{ Pack-years } & \multicolumn{2}{|c|}{ Quit years (year) } \\
\hline \multicolumn{10}{|c|}{ Adenocarcinoma $[\leq 2 \mathrm{~cm}]$} \\
\hline \multicolumn{10}{|l|}{ LY } \\
\hline Present & 15 & $10[0-40]$ & 0.45 & 23 [0-62] & 0.38 & $23[0-64]$ & 0.33 & $22[0-81]$ & 0.50 \\
\hline \multicolumn{10}{|l|}{ VI } \\
\hline Present & 21 & $5[0-50]$ & 0.44 & $3[0-60]$ & 0.50 & $1.5[0-105]$ & 0.28 & $33[0-80]$ & 0.27 \\
\hline Absent & 174 & $0[0-80]$ & & $0[0-67]$ & & 0 [0-232] & & $52[0-87]$ & \\
\hline \multicolumn{10}{|l|}{ PL } \\
\hline \multicolumn{10}{|c|}{ Adenocarcinoma $[2-3 \mathrm{~cm}]$} \\
\hline \multicolumn{10}{|l|}{ LY } \\
\hline Present & 22 & 20 [0-30] & 0.50 & $36[0-61]$ & 0.12 & $36[0-705]$ & 0.35 & $17[0-80]$ & 0.13 \\
\hline Absent & 66 & $8[0-60]$ & & 13 [0-67] & & $4.8[0-103]$ & & $42[0-84]$ & \\
\hline \multicolumn{10}{|l|}{ VI } \\
\hline Present & 43 & $20[0-60]$ & 0.02 & $40[0-61]$ & $<0.01$ & $40[0-100]$ & $<0.01$ & $9[0-81]$ & 0.01 \\
\hline Absent & 45 & $0[0-50]$ & & $0[0-67]$ & & 0 [0-103] & & 63 [0-84] & \\
\hline \multicolumn{10}{|l|}{ PL } \\
\hline Absent & 31 & $4[0-40]$ & & 20 [0-68] & & 9 [0-108] & & 15 [0-83] & \\
\hline \multicolumn{10}{|l|}{ VI } \\
\hline Present & 22 & 9 [0-40] & 0.76 & 29 [0-60] & 0.93 & $8.4[0-77]$ & 0.79 & 13 [0-83] & 0.90 \\
\hline Absent & 20 & 7 [0-40] & & 22 [0-68] & & $8.4[0-108]$ & & 19 [0-81] & \\
\hline \multicolumn{10}{|l|}{ PL } \\
\hline Present & 21 & 12 [0-40] & 0.83 & 32 [0-68] & 0.97 & 8 [0-108] & 0.78 & 13 [0-83] & 0.61 \\
\hline Absent & 21 & 4 [0-40] & & 34 [0-60] & & $10[0-80]$ & & 5 [0-81] & \\
\hline
\end{tabular}

LY, lymphatic permeation; VI, vascular invasion; PL, pleural invasion 
Table 7 Univariate analysis of postoperative survival according to smoking history among adenocarcinoma patients

\begin{tabular}{|c|c|c|c|c|c|c|c|}
\hline Factors & $\mathrm{n}$ & \multicolumn{2}{|l|}{ OS } & \multicolumn{2}{|l|}{ RFS } & \multicolumn{2}{|l|}{ DSS } \\
\hline \multicolumn{8}{|c|}{ Lepidic adenocarcinoma } \\
\hline \multicolumn{8}{|c|}{ Smoking } \\
\hline Ever & 54 & $1.64(0.47-5.71)$ & 0.44 & $1.58(0.51-4.94)$ & 0.43 & $1.72(0.11-27.6)$ & 0.70 \\
\hline \multicolumn{8}{|c|}{ Papillary adenocarcinoma } \\
\hline \multicolumn{8}{|c|}{ Smoking } \\
\hline Ever & 63 & 1.59 (0.64-3.93) & 0.31 & $1.50(0.71-3.15)$ & 0.29 & $1.28(0.43-3.86)$ & 0.66 \\
\hline Never & 52 & 1 & & 1 & & 1 & \\
\hline \multicolumn{8}{|c|}{ Smoking } \\
\hline Ever & 36 & $2.11(0.56-7.99)$ & 0.27 & $2.29(0.87-6.03)$ & 0.09 & $1.60(0.29-8.77)$ & 0.59 \\
\hline Never & 26 & 1 & & 1 & & 1 & \\
\hline \multicolumn{8}{|c|}{ Solid adenocarcinoma } \\
\hline \multicolumn{8}{|c|}{ Smoking } \\
\hline Ever & 16 & $22.8(0.00-4,752)$ & 0.67 & $23.2(0.00-1,427)$ & 0.58 & $22.9(0.00-2,840)$ & 0.74 \\
\hline Never & 1 & 1 & & 1 & & 1 & \\
\hline \multicolumn{8}{|c|}{ Adenocarcinoma with micropapillary component } \\
\hline \multicolumn{8}{|c|}{ Smoking } \\
\hline
\end{tabular}

OS, overall survival; RFS, recurrence free survival; DSS, diseases specific survival; HR, hazard ratio; $\mathrm{Cl}$, confidence interval.

Table 8 Univariate analysis of postoperative survival according to smoking history among adenocarcinoma patients

\begin{tabular}{|c|c|c|c|c|c|c|c|c|c|}
\hline Factors & $\mathrm{n}$ & \multicolumn{2}{|c|}{ Cigarettes per day } & \multicolumn{2}{|c|}{ Years of smoking (year) } & \multicolumn{2}{|c|}{ Pack-years } & \multicolumn{2}{|c|}{ Quit years (year) } \\
\hline \multicolumn{10}{|c|}{ Lepidic adenocarcinoma } \\
\hline \multicolumn{10}{|l|}{ LY } \\
\hline Present & 7 & 0 [0-20] & 0.71 & $0[0-30]$ & 0.78 & 0 [0-30] & 0.94 & 68 [0-81] & 0.59 \\
\hline \multicolumn{10}{|l|}{$\mathrm{VI}$} \\
\hline Present & 6 & $10[0-20]$ & 0.46 & $8[0-41]$ & 0.83 & $7.5[0-41]$ & 0.69 & $58[6-80]$ & 0.62 \\
\hline Absent & 121 & $0[0-60]$ & & 0 [0-68] & & $0[0-147]$ & & $61[0-84]$ & \\
\hline
\end{tabular}

Table 8 (continued) 
Table 8 (continued)

\begin{tabular}{|c|c|c|c|c|c|c|c|c|c|}
\hline Factors & $\mathrm{n}$ & \multicolumn{2}{|c|}{ Cigarettes per day } & \multicolumn{2}{|c|}{ Years of smoking (year) } & \multicolumn{2}{|c|}{ Pack-years } & \multicolumn{2}{|c|}{ Quit years (year) } \\
\hline \multicolumn{10}{|l|}{ PL } \\
\hline Present & 12 & $18[0-40]$ & 0.01 & 23 [0-68] & 0.04 & $12.5[0-100]$ & 0.05 & 27 [0-80] & 0.25 \\
\hline Absent & 115 & $0[0-60]$ & & $0[0-61]$ & & $0[0-147]$ & & $65[0-84]$ & \\
\hline \multicolumn{10}{|c|}{ Papillary adenocarcinoma } \\
\hline \multicolumn{10}{|l|}{ LY } \\
\hline Present & 22 & $9[0-40]$ & 0.88 & 27 [0-62] & 0.36 & $8.4[0-69]$ & 0.63 & $14[0-80]$ & 0.19 \\
\hline Absent & 93 & $5[0-60]$ & & $3[0-67]$ & & $1.5[0-90]$ & & 40 [0-82] & \\
\hline \multicolumn{10}{|l|}{ VI } \\
\hline \multicolumn{10}{|l|}{ PL } \\
\hline Present & 32 & 18 [0-60] & 0.08 & $36[0-62]$ & 0.02 & $41[0-90]$ & 0.02 & $2[0-81]$ & $<0.01$ \\
\hline Absent & 83 & $2[0-50]$ & & $0[0-67]$ & & $0.3[0-90]$ & & 42 [0-82] & \\
\hline \multicolumn{10}{|c|}{ Acinar adenocarcinoma } \\
\hline \multicolumn{10}{|l|}{ LY } \\
\hline Present & 12 & $15[0-40]$ & 0.62 & $38[0-61]$ & 0.23 & $30[0-80]$ & 0.37 & $13[0-77]$ & 0.52 \\
\hline Absent & 50 & $10[0-80]$ & & $10[0-61]$ & & $6.5[0-232]$ & & $24[0-87]$ & \\
\hline \multicolumn{10}{|l|}{ VI } \\
\hline \multicolumn{10}{|l|}{ PL } \\
\hline \multicolumn{10}{|c|}{ Solid adenocarcinoma } \\
\hline \multicolumn{10}{|l|}{ LY } \\
\hline Present & 7 & 30 [20-30] & 0.60 & $47[5-53]$ & 0.81 & $53[5-77]$ & 0.67 & 3 [0-53] & 0.54 \\
\hline Absent & 10 & 20 [0-50] & & 39 [0-60] & & $36[0-108]$ & & $0[0-78]$ & \\
\hline \multicolumn{10}{|l|}{$\mathrm{VI}$} \\
\hline Present & 11 & $30[0-40]$ & 0.96 & $37[0-51]$ & 0.05 & $52.5[0-76.6]$ & 0.59 & $0[0-0]$ & $<0.01$ \\
\hline Absent & 6 & $23[3-50]$ & & 52 [37-60] & & $49.6[9-108]$ & & $5[0-78]$ & \\
\hline \multicolumn{10}{|l|}{ PL } \\
\hline Present & 7 & $30[6-40]$ & 0.19 & $37[5-54]$ & 0.48 & $64.5[4.5-108]$ & 0.54 & $4[0-53]$ & 0.16 \\
\hline Absent & 10 & 20 [0-50] & & 49 [0-60] & & $48.6[0-103]$ & & $0[0-0]$ & \\
\hline
\end{tabular}

Table 8 (continued) 
Table 8 (continued)

\begin{tabular}{|c|c|c|c|c|c|c|c|c|c|}
\hline Factors & $\mathrm{n}$ & \multicolumn{2}{|c|}{ Cigarettes per day } & \multicolumn{2}{|c|}{ Years of smoking (year) } & \multicolumn{2}{|c|}{ Pack-years } & \multicolumn{2}{|c|}{ Quit years (year) } \\
\hline \multicolumn{10}{|c|}{ Adenocarcinoma with micropapillary component } \\
\hline \multicolumn{10}{|l|}{ LY } \\
\hline Present & 8 & $13[0-40]$ & 0.74 & $24[0-57]$ & 0.44 & $25.4[0-64]$ & 0.54 & $15[0-77]$ & 0.80 \\
\hline \multicolumn{10}{|l|}{ VI } \\
\hline Present & 15 & $10[0-40]$ & 0.97 & $2[0-57]$ & 0.89 & $0.4[0-94]$ & 0.81 & $16[0-81]$ & 0.81 \\
\hline Absent & 19 & $10[0-50]$ & & $10[0-61]$ & & $0.3[0-61]$ & & $48[0-77]$ & \\
\hline \multicolumn{10}{|l|}{ PL } \\
\hline
\end{tabular}

LY, lymphatic permeation; VI, vascular invasion; PL, pleural invasion.

smokers (Table 9 and Figure 3). This indicates that at least 10 years of smoking cessation may be needed to achieve similar postoperative prognosis as that of non-smokers in cases of adenocarcinomas $\leq 3 \mathrm{~cm}$. In contrast, adenocarcinomas $>3 \mathrm{~cm}$ may grow and invade independent of the preoperative smoking status.

\section{Discussion}

Pathological factors including LY, VI, and PL were significantly related to the degree of preoperative smoking in adenocarcinomas, particularly those with invasive diameters of $2-3 \mathrm{~cm}$, whereas such a relationship was not identified in non-adenocarcinomas. As multiple studies have stated, our findings agree that some clinicopathological factors, including VI and PL, were unfavorable prognostic factors in surgically resected early-stage NSCLC (Tables 2,3) (4-6). Obviously, these pathological findings represent the process of metastasis of the tumor cells. As summarized in Tables 4-6, smoking would promote this process, particularly in adenocarcinomas $\leq 3 \mathrm{~cm}$, which indicates that the malignant extent of adenocarcinoma in heavy smokers is relatively high and could lead to poor prognosis, despite the small size. Indeed, some clinical trials have demonstrated that chest screening tests, including screening CT, are recommended for high-risk patients with 30 or more pack-years of smoking (20). Needless to say, in addition to regular examinations of the chest, early interventions such as surgery are essential for current/exsmokers with NSCLC to improve their survival.

Ideally, all smokers should quit smoking for the prevention of NSCLC. Although there is a reduction in the numbers of smokers worldwide, several still love smoking (21). There is inadequate information regarding the duration of smoking cessation prior to the diagnosis of stage I NSCLC that may result in outcomes and prognosis in smokers similar to that in non-smokers. Such information, if available, may be useful in encouraging smokers to quit. In this study, we also evaluated the number of years of smoking cessation that would provide postoperative survival benefits to former smokers with small lung adenocarcinomas. Our findings suggest that $\geq 10$ years of smoking cessation would improve RFS following resection. Zhou et al. reported that the benefit of smoking cessation is obtained after $\geq 9$ years of smoking cessation in patients with NSCLC when compared with current smokers (19). Although that study included advanced NSCLC including squamous cell carcinomas, they reported similar findings as observed in our study. These data suggest that prolonged smoking cessation could inhibit the progression of lung cancer. This merit of smoking cessation should be conveyed to current smokers as it may result in significant survival benefits.

We also found a strong relationship between the histological subtypes of adenocarcinoma and smoking. PL correlated with smoking in lepidic and papillary adenocarcinomas, and VI was related to smoking in acinar 
Table 9 Correlation of pathological factors and smoking cessation years according to invasive size of adenocarcinoma

\begin{tabular}{|c|c|c|c|c|c|c|c|c|c|c|c|c|c|c|c|}
\hline Factors & \multicolumn{3}{|c|}{ Never + 5 y.c. } & \multicolumn{3}{|c|}{ Never + 10 y.c. } & \multicolumn{3}{|c|}{ Never + 15 y.c. } & \multicolumn{3}{|c|}{ Never +20 y.c. } & \multicolumn{3}{|c|}{ Never } \\
\hline \multicolumn{16}{|c|}{ Adenocarcinoma $(\leq 2 \mathrm{~cm})$} \\
\hline \multicolumn{16}{|l|}{ LY } \\
\hline Present & 4 & 11 & 0.50 & 6 & 9 & 0.20 & 7 & 8 & 0.14 & 7 & 8 & 0.25 & 8 & 7 & 0.79 \\
\hline \multicolumn{16}{|l|}{ VI } \\
\hline Present & 5 & 16 & 0.57 & 8 & 13 & 0.17 & 9 & 12 & 0.13 & 10 & 11 & 0.14 & 11 & 10 & 0.65 \\
\hline Absent & 33 & 141 & & 39 & 135 & & 47 & 127 & & 53 & 121 & & 81 & 93 & \\
\hline \multicolumn{16}{|l|}{ PL } \\
\hline \multicolumn{16}{|c|}{ Adenocarcinoma $(2-3 \mathrm{~cm})$} \\
\hline \multicolumn{16}{|l|}{ LY } \\
\hline Present & 8 & 14 & 0.28 & 10 & 12 & 0.21 & 10 & 12 & 0.62 & 12 & 10 & 0.23 & 15 & 7 & 0.32 \\
\hline Absent & 16 & 50 & & 20 & 46 & & 25 & 41 & & 26 & 40 & & 35 & 31 & \\
\hline \multicolumn{16}{|l|}{$\mathrm{VI}$} \\
\hline Present & 13 & 30 & 0.64 & 22 & 21 & 0.01 & 24 & 19 & 0.01 & 25 & 18 & 0.01 & 31 & 12 & 0.01 \\
\hline Absent & 11 & 34 & & 8 & 37 & & 11 & 34 & & 13 & 32 & & 19 & 26 & \\
\hline \multicolumn{16}{|l|}{$\mathrm{PL}$} \\
\hline Absent & 13 & 18 & & 13 & 18 & & 15 & 16 & & 17 & 14 & & 19 & 12 & \\
\hline \multicolumn{16}{|l|}{ VI } \\
\hline Present & 9 & 13 & 1.00 & 9 & 13 & 1.00 & 13 & 9 & 0.54 & 13 & 9 & 1.00 & 15 & 7 & 0.75 \\
\hline Absent & 8 & 12 & & 9 & 11 & & 9 & 11 & & 11 & 9 & & 12 & 8 & \\
\hline \multicolumn{16}{|l|}{ PL } \\
\hline Present & 8 & 13 & 1.00 & 8 & 13 & 0.76 & 11 & 10 & 1.00 & 11 & 10 & 0.76 & 13 & 8 & 1.00 \\
\hline Absent & 9 & 12 & & 10 & 11 & & 11 & 10 & & 13 & 8 & & 14 & 7 & \\
\hline
\end{tabular}

LY, lymphatic permeation; VI, vascular invasion; PL, pleural invasion; y.c., year cessation; nv., never. 

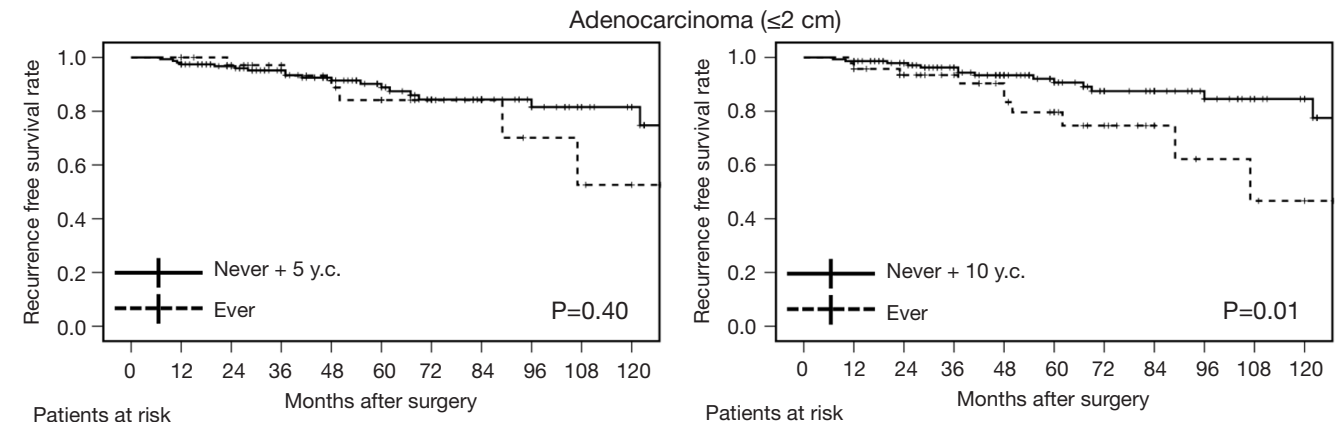

\begin{tabular}{cccccccccccc} 
& 0 & 12 & 24 & 36 & 48 & 60 & 72 & 84 & 96 & 108 & 120 \\
\hline Nv. +5 & 157 & 148 & 127 & 106 & 83 & 65 & 47 & 36 & 27 & 18 & 12 \\
\hline Ever & 38 & 36 & 30 & 25 & 20 & 15 & 12 & 6 & 4 & 3 & 1
\end{tabular}
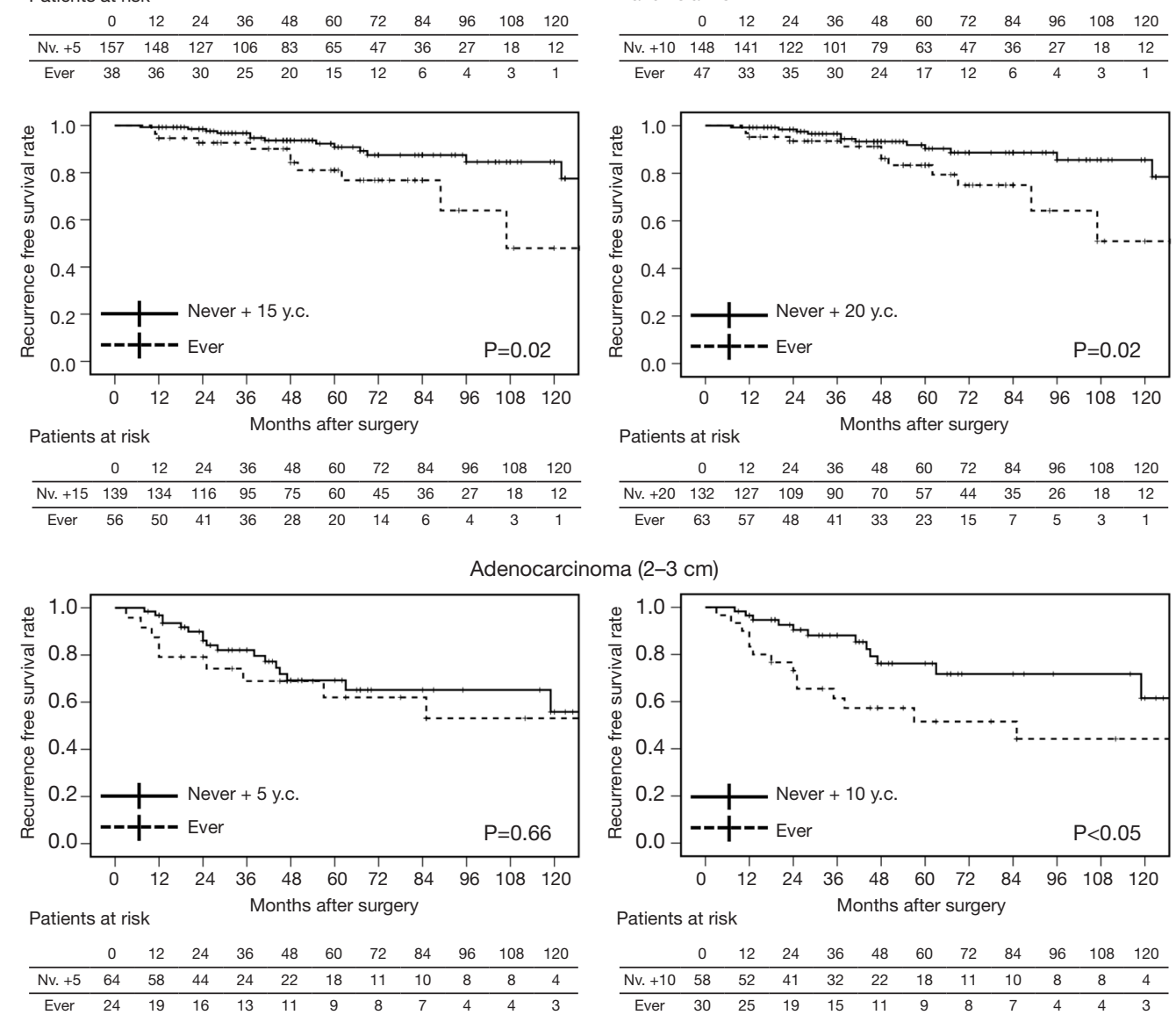

Patients at risk
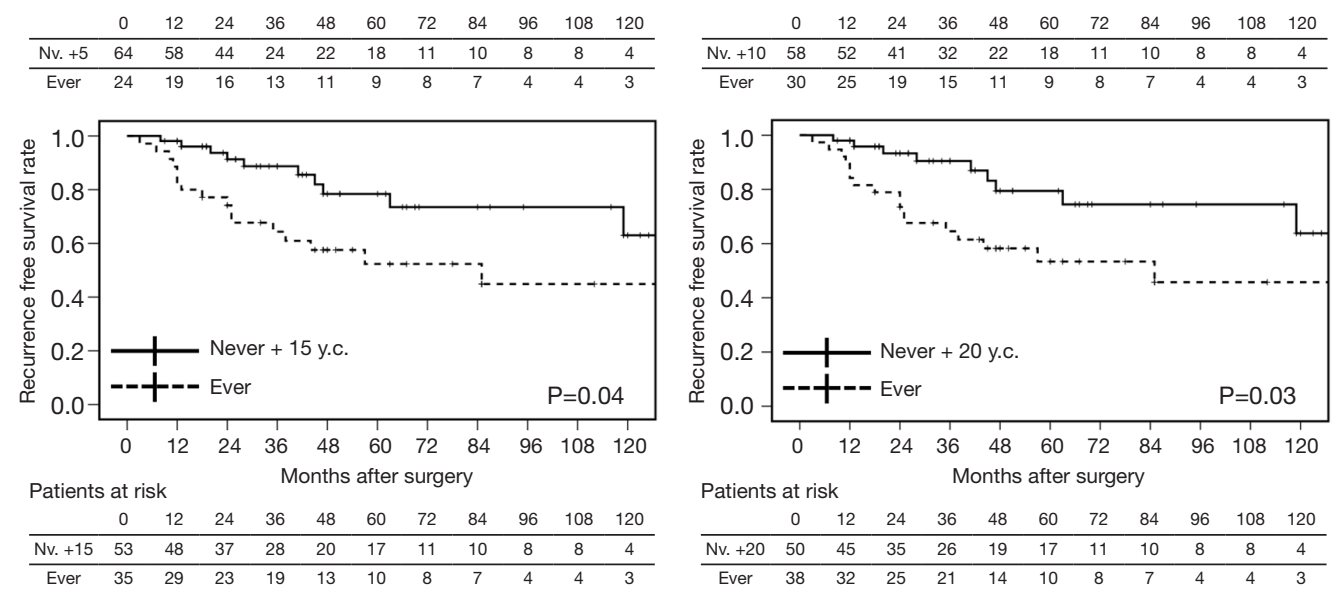

Figure 3 Comparison of recurrence-free survival for adenocarcinoma of various sizes ( $\leq 2$ and $2-3 \mathrm{~cm}$ ) of former smokers with $\geq X$ years of cessation (y.c.) combined with nonsmokers (never $+\mathrm{X}$ y.c.). 
and solid adenocarcinomas. Few studies have investigated the differences in the invasion pattern of the various histological subtypes. However, it is certain and quite interesting that smoking accelerates the malignant potential of adenocarcinomas in accordance with the invasive features of the respective predominant patterns.

Smoking is usually evaluated in "pack-years". We also examined the number of cigarettes per day, smoking years, and smoking cessation years. Similar tendencies regarding the relationships with pathological factors were observed (Tables 5,6,8). Although we cannot comment on the evaluation method best suitable to predict postoperative survival in these patients, smoking is certainly associated with local invasion and progression of lung adenocarcinomas.

This study has some limitations. First, this was a retrospective study at single Institute; therefore, patient selection bias and time trend bias are inevitable. Second, we did not include the postoperative treatments such as adjuvant therapy and post-recurrence treatment in our analyses. Genetic differences may influence these treatment modalities, which could prolong survival after surgery and relapse. Third, we did not focus on postoperative smoking status because we did not ask patients if they had resumed smoking following surgery in every follow-up clinic. We also did not collect information regarding second-hand smoking. Fourth, our analyses regarding smoking history were based on medical records. Objective measurements such as carboxyhemoglobin and cotinine may have been more reliable biomarkers to evaluate tobacco smoking exposure. Fifth, in the analyses of non-adenocarcinomas, it is possible that true probability may not have been obtained owing to the small sample size. Additionally, postoperative survival for each segment of smoking cessation period should be compared to confirm the number of years after cessation that can improve the postoperative survival (e.g., never vs. 5 y.c. vs. 10 y.c. vs. 15 y.c. vs. 20 y.c.). Further investigations with a larger number of patients are required to substantiate our findings.

\section{Conclusions}

Smoking promotes tumor progression, which is represented by VI and PL, particularly in pathological stage I adenocarcinomas measuring $2-3 \mathrm{~cm}$. Larger adenocarcinomas and non-adenocarcinomas of any size may grow and become invasive independent of the preoperative smoking status. Ten or more years of smoking cessation may have associated postoperative survival benefits. Outcomes appear to be proportionally related to the duration of smoking cessation. Therefore, current smokers should quit smoking to ensure longer survival even though they suffer from small-sized lung adenocarcinomas in the future.

\section{Acknowledgments}

Funding: This work was supported by JSPS KAKENHI (Grant Number 17K16617).

\section{Footnote}

Reporting Checklist: The authors have completed the STROBE reporting checklist. Available at http://dx.doi. org/10.21037/tlcr-20-465

Data Sharing Statement: Available at http://dx.doi. org/10.21037/tlcr-20-465

Peer Review File: Available at http://dx.doi.org/10.21037/ tlcr-20-465

Conflicts of Interest: All authors have completed the ICMJE uniform disclosure form (available at http://dx.doi. org/10.21037/tlcr-20-465). TS reports grants from JSPS KAKENHI, during the conduct of the study. The other authors have no conflicts of interest to declare.

Ethical Statement: The authors are accountable for all aspects of the work in ensuring that questions related to the accuracy or integrity of any part of the work are appropriately investigated and resolved. This study was approved by our institutional review board in March 2020 (approved number \#2483). The requirement of informed consent was waived due to the retrospective design of the study and because no personally identifiable information was collected. Clinical data including smoking history were recorded by medical staff (nurses and/or doctors) and used for statistical analysis. All procedures performed in this study were in accordance with the Declaration of Helsinki (as revised in 2013).

Open Access Statement: This is an Open Access article distributed in accordance with the Creative Commons Attribution-NonCommercial-NoDerivs 4.0 International License (CC BY-NC-ND 4.0), which permits the noncommercial replication and distribution of the article with 
the strict proviso that no changes or edits are made and the original work is properly cited (including links to both the formal publication through the relevant DOI and the license). See: https://creativecommons.org/licenses/by-nc-nd/4.0/.

\section{References}

1. Nanavaty P, Alvarez MS, Alberts WM. Lung cancer screening: Advantages, controversies, and applications. Cancer Control 2014;21:9-14.

2. Howington JA, Blum MG, Chang AC, et al. Treatment of stage I and II non-small cell lung cancer: Diagnosis and management of lung cancer, 3rd ed: American college of chest physicians evidence-based clinical practice guidelines. Chest 2013;143:e278S-e313S.

3. Sawabata N, Miyaoka E, Asamura H, et al. Japanese lung cancer registry study of 11,663 surgical cases in 2004: Demographic and prognosis changes over decade. J Thorac Oncol 2011;6:1229-35.

4. Yoshida J, Nagai K, Asamura H, et al. Visceral pleura invasion impact on non-small cell lung cancer patient survival: Its implications for the forthcoming TNM staging based on a large-scale nation-wide database. J Thorac Oncol 2009;4:959-63.

5. Harada M, Hato T, Horio H. Intratumoral lymphatic vessel involvement is an invasive indicator of completely resected pathologic stage I non-small cell lung cancer. J Thorac Oncol 2011;6:48-54.

6. Kinoshita T, Ohtsuka T, Yotsukura M, et al. Prognostic impact of preoperative tumor marker levels and lymphovascular invasion in pathological stage I adenocarcinoma and squamous cell carcinoma of the lung. J Thorac Oncol 2015;10:619-28.

7. Rami-Porta R, Bolejack V, Crowley J, et al. The iaslc lung cancer staging project: Proposals for the revisions of the $t$ descriptors in the forthcoming eighth edition of the TNM classification for lung cancer. J Thorac Oncol 2015;10:9901003.

8. Wynder EL, Muscat JE. The changing epidemiology of smoking and lung cancer histology. Environ Health Perspect 1995;103:143-8.

9. Nakamura H, Saji H. Worldwide trend of increasing primary adenocarcinoma of the lung. Surg Today 2014;44:1004-12.

10. Stellman SD, Muscat JE, Thompson S, et al. Risk of squamous cell carcinoma and adenocarcinoma of the lung in relation to lifetime filter cigarette smoking. Cancer 1997;80:382-8.
11. Fernandez FG, Kosinski AS, Burfeind W, et al. The society of thoracic surgeons lung cancer resection risk model: Higher quality data and superior outcomes. Ann Thorac Surg 2016;102:370-7.

12. Shewale JB, Correa AM, Brown EL, et al. Time trends of perioperative outcomes in early stage non-small cell lung cancer resection patients. Ann Thorac Surg 2020;109:404-11.

13. Hofmann D, Hofmann I. The changing cigarette, 19501995. J Toxicol Environ Health 1997;50:307-64.

14. Travis WD, Brambilla E, Noguchi M, et al. International Association for the Study of Lung Cancer/American Thoracic Society/European Respiratory Society International multidisciplinary classification of lung adenocarcinoma. J Thorac Oncol 2011;6:244-85.

15. Goldstraw P, Chansky K, Crowley J, et al. The iaslc lung cancer staging project: Proposals for revision of the TNM stage groupings in the forthcoming (eighth) edition of the TNM classification for lung cancer. J Thorac Oncol 2016;11:39-51.

16. Travis WD, Asamura H, Bankier AA, et al. The iaslc lung cancer staging project: Proposals for coding t categories for subsolid nodules and assessment of tumor size in partsolid tumors in the forthcoming eighth edition of the TNM classification of lung cancer. J Thorac Oncol 2016;11:1204-23.

17. Travis WD, Brambilla E, Nicholson AG, et al. The 2015 world health organization classification of lung tumors: Impact of genetic, clinical and radiologic advances since the 2004 classification. J Thorac Oncol 2015;10:1243-60.

18. Pyo JS, Kim JH. Clinicopathological significance of micropapillary pattern in lung adenocarcinoma. Pathol Oncol Res 2018;24:547-55.

19. Zhou W, Heist RS, Liu G, et al. Smoking cessation before diagnosis and survival in early stage non-small cell lung cancer patients. Lung Cancer 2006;53:375-80.

20. Bravo-Iñiguez CE, Fox SW, De Leon LE, et al. Cumulative nonsmoking risk factors increase the probability of developing lung cancer. J Thorac Cardiovasc Surg 2019;158:1248-54.e1.

21. Samet JM. Tobacco smoking: the leading cause of preventable disease worldwide. Thorac Surg Clin 2013;23:103-12.

Cite this article as: Shima T, Kinoshita T, Uematsu M, Sasaki N, Sugita Y, Shimizu R, Harada M, Hishima T, Horio H. How long is cessation of preoperative smoking required to improve postoperative survival of patients with pathological stage I nonsmall cell lung cancer? Transl Lung Cancer Res 2020;9(5):19241939. doi: $10.21037 /$ tlcr-20-465 